\title{
Safety of neural stem cell transplantation in patients with severe traumatic brain injury
}

\author{
ZHIGANG WANG, YONG LUO, LVAN CHEN and WU LIANG \\ Department of Neurosurgery, The First People's Hospital of Jingmen, Jingmen, Hubei 448000, P.R. China
}

Received February 11, 2016; Accepted February 24, 2017

DOI: 10.3892/etm.2017.4423

\begin{abstract}
Neural stem cell (NSC) therapy is a promising treatment for traumatic brain injury (TBI). In addition, mesenchymal stem cells (MSCs) have been investigated for the treatment of TBI due to their functions in neural regeneration and their neurotrophic effect. In the present study, the safety, feasibility and biological effects of autologous MSC-derived NSC-like cell transplantation were investigated in 10 patients with severe TBI. All patients received intravenous or intrathecal injections of human NSC-like cells and were evaluated with physical and neurological examinations, routine laboratory tests and neuroradiological findings. The results indicated that the majority of patients experienced improved neurological function in different degrees during the follow-up period. No mortality or serious adverse events were observed in any patient subsequent to transplantation. Higher serum levels of nerve growth factor and brain-derived neurotrophic factor were detected following the transplantation, as compared with the levels prior to treatment. Overall, the present results suggest that transplantation of autologous NSC-like cells is feasible and appears to be safe for the treatment of non-acute severe TBI.
\end{abstract}

\section{Introduction}

Traumatic brain injury (TBI) is a major cause of mortality and disability, particularly among young adults in developed countries (1-3). The incidence of head injury is $~ 300$ per 100,000 people per year, with a mortality of 25 per 100,000 people in the United States (4). Although trauma management systems and surgical techniques have improved, the overall mortality rate in severe TBI is still 25\% (4). Among all types of injury, brain injury is highly likely to result in mortality or permanent disability. Patients who survive TBI potentially face long-lasting effects, which also affects the

Correspondence to: Dr Wu Liang, Department of Neurosurgery, The First People's Hospital of Jingmen, 67 Xiangshan Road, Jingmen, Hubei 448000, P.R. China

E-mail: 360234044@qq.com

Key words: cell transplantation, traumatic brain injury, stem cell patients' families and communities. Although rehabilitation therapy is important for maximizing functional recovery following TBI, there are limited effective clinical methods for recovery after neurological impairments are treated (5). Therefore, any therapy that may improve the recovery process may be helpful (6).

In recent years, several studies have investigated the potential neuroprotective effects of stem cells and their ability to stimulate endogenous regeneration in animal models of TBI (7-11). Although the functional mechanisms of this therapy have yet to be determined, these previous studies demonstrated that stem cell administration improves functional recovery following TBI in experimental animals. In addition, transplantation of stem cells has been successfully used in a clinical trial for patients with amyotrophic lateral sclerosis, multiple sclerosis and cerebral palsy (12-14). Thus, stem cell transplantation may be an attractive approach to restore brain function after TBI in humans. However, to date, few clinical studies have evaluated stem cell transplantation in patients with TBI (15).

An exploratory trial was performed in the present study using neural stem cell (NSC)-like cells derived from autologous bone marrow mesenchymal stem cells (MSCs) in 10 patients with severe TBI. The aim of the current study was to perform a phase I study in order to assess the safety, feasibility and biological effects of intravenous or intrathecal autologous MSC-derived NSC-like cell transplantation in patients with severe TBI. In addition, the study reports on our experience with this type of trial design, including patient recruitment, pre- and post-treatment monitoring, and identification of adverse events in the current clinical trial.

\section{Materials and methods}

Study design and patient enrolment. The present study reports the observations on 10 patients enrolled in a protocol designed to assess the safety and feasibility of autologous human MSC-derived NSC-like cell infusion at the First People's Hospital of Jingmen (Jingmen, China) between January 2012 and June 2013. The study protocol was approved by the Ethics Committees of the First People's Hospital of Jingmen. Written informed consent was obtained from the immediate families of all patients. Patients were enrolled into this study if they fulfilled all of the following inclusion criteria: i) Age ranging between 18 and 60 years; ii) patient suffering from a severe TBI 
classified with a Glasgow Coma Scale (GCS) score of 3-8 (16) within $48 \mathrm{~h}$ from the trauma; iii) TBI was assessed by head computed tomography or magnetic resonance imaging (MRI); iv) the time of TBI onset was within the past 60 days; and v) written informed consent had been obtained. Furthermore, patients were excluded if they met any of the following criteria: i) TBI was combined with other internal organ injuries; ii) patients with an allergic constitution or with a history of severe allergies; iii) presence of severe complications, such as cardiac, renal or hepatic dysfunction; iv) hemodynamic or respiratory instability; v) pregnant or possibly pregnant; and vi) patients with cancer or malignant diseases.

Preparation and transplantation of autologous NSC-like cells. In order to prepare NSC-like cells, bone marrow aspiration, isolation and cultivation of MSCs, induction of NSCs and cell preparation were performed as previously described $(14,17)$. Briefly, $5 \mathrm{ml}$ bone marrow was obtained by puncture in the posterior iliac crest of each patient according to the conventional bone marrow aspiration procedures. Bone marrow mononuclear cells were then separated by Percoll density gradient centrifugation at $500 \mathrm{xg}$ for $10 \mathrm{~min}\left(37^{\circ} \mathrm{C}\right)$ and cultured in a flask with low glucose Dulbecco's modified Eagle medium (Thermo Fisher Scientific, Inc., Waltham, MA, USA) containing 10\% fetal bovine serum (Hyclone; GE Healthcare, Chicago, IL, USA) and $1 \%$ penicillin-streptomycin (Thermo Fisher Scientific, Inc.) at $37^{\circ} \mathrm{C}$ and $5 \% \mathrm{CO}_{2}$. The media were changed every $2-3$ days. All cell isolation and manipulation procedures were conducted in a laminar flow cabinet with sterile equipment. Only cells with a positive signal for the multipotential markers, octamer-binding transcription factor 4 (Oct4) and Nanog, were screened for further cloning, culturing and inducing.

In order to determine which cells had a positive signal for Oct4 and Nanog, MSCs were fixed in 4\% paraformaldehyde at room temperature for $15 \mathrm{~min}$. Following this, MSCs were blocked with 3\% bovine serum albumin (Sigma-Aldrich; Merck KGaA, Darmstadt, Germany) at room temperature for $30 \mathrm{~min}$. Cells were then incubated with primary antibodies against Nanog $(1: 1,000 ; 3580 S)$ and Oct4 $(1: 1,000 ;$ hz1005a $)$ for $1 \mathrm{~h}$ at room temperature. Following this, cells were washed three times with phosphate-buffered saline, for $5 \mathrm{~min}$ each. Subsequently, the cells were incubated with rat anti-rabbit phycoerythrin-labelled secondary antibody (1:200; ASS3404) for $1 \mathrm{~h}$ at room temperature. All antibodies were supplied by Shanghai Westang Bio-Tech Co., Ltd., (Shanghai, China). The cells were then visualized under a fluorescent microscope.

When the primary MSCs had expanded to $30-40 \%$ confluence, a combination of $20 \mathrm{ng} / \mathrm{ml}$ recombinant human basic fibroblast growth factor (bFGF) (Prospec-Tany TechnoGene, Ltd., East Brunswick, NJ, USA) and $10 \mathrm{nM}$ retinoic acid (Shanghai Westang Bio-Tech Co., Ltd.) was added to the medium for $12 \mathrm{~h}$ to induce the MSC differentiation into NSC-like cells. Cell viability was evaluated by trypan blue staining at the end of the harvest and prior to infusion, and was estimated to be $>90 \%$ in all samples. No chromosomal aberrations were observed for the induced NSC-like cells. In addition, the cell culture was tested for sterility, and there was no evidence of bacterial, fungal, viral or mycoplasma contamination in any of the samples, ensuring the safety of the cells prior to the transplantations. The NSC-like cells were detached, washed three times with normal saline solution and then resuspended in normal saline with 5\% human serum albumin (Sigma-Aldrich; Merck KGaA). In total, 7 patients received an intravenous injection of NSC-like cells diluted with $100 \mathrm{ml}$ saline. The other 3 patients received an intrathecal injection of NSC-like cells in $2 \mathrm{ml}$ normal saline solution via a standard lumbar puncture. All patients received two doses of dexamethasone (5 mg, intravenous; Shanghai General Pharmaceutical Co., Ltd., Shanghai, China) immediately prior to and after the cell transplantation.

Patient evaluation. All enrolled patients were evaluated according to a protocol that included thorough physical and neurological examinations, routine laboratory tests and neuroradiological findings, with a primary outcome of safety and feasibility (adverse events, neurological worsening and evidence of tumor formation). The outcome of patients was assessed at 6 months post-transplantation based on the Glasgow Outcome Scale (GOS) (18), with a score of 1 indicating mortality and score of 5 indicating recovery. In addition, the neurological status of patients was evaluated using the National Institute of Health Stroke Scale (NIHSS) (19) and GCS scoring systems on the day of transplantation, and at 1, 3, 7, 30 and 60 days after cell infusion. The NIHSS scores were as follows: 0 , no evident stroke symptoms; $1-4$, mild stroke; $5-15$, moderate stroke; 16-20, moderate to severe stroke; and 21-42, severe stroke. Routine laboratory tests (complete blood count and comprehensive metabolic panel) were also conducted at the aforementioned time points. Brain MRI scans were performed in all patients prior to and following infusion.

Measurement of neurotrophic factors in the serum. Peripheral blood samples were collected from patients prior to the procedure, and at 3 and 7 days after transplantation. The blood samples were analyzed by enzyme-linked immunosorbent assay for the determination of the serum levels of brain-derived neurotrophic factor (BDNF; EK-H11287) and nerve growth factor (NGF; EK-H11487), according to the manufacturer's instructions (Shanghai Westang Bio-Tech Co., Ltd.).

Statistical analysis. All data are presented as the mean \pm standard deviation. The SPSS version 13.0 software (SPSS, Inc., Chicago, IL, USA) was used for statistical analysis of the data. The measurements were statistically evaluated using one-way analysis of variance followed by the Bonferroni-Dunn post-hoc test. A value of $\mathrm{P}<0.05$ was considered to indicate that differences were statistically significant.

\section{Results}

Baseline characteristics of patients. The main characteristics of the 10 patients are presented in Table I. In summary, 3 female and 7 male patients with a mean age of $38.10 \pm 12.73$ years (range, 21-55 years) were enrolled. Patients received intravenous ( 7 patients) or intrathecal (3 patients) NSC-like cell infusion at 20-60 days after severe TBI (GCS score, 6-8). All patients were treated according to the standardized guidelines for the management of severe TBI (20). In total, 5 of the patients received decompressive craniectomy during the acute stage of TBI. 


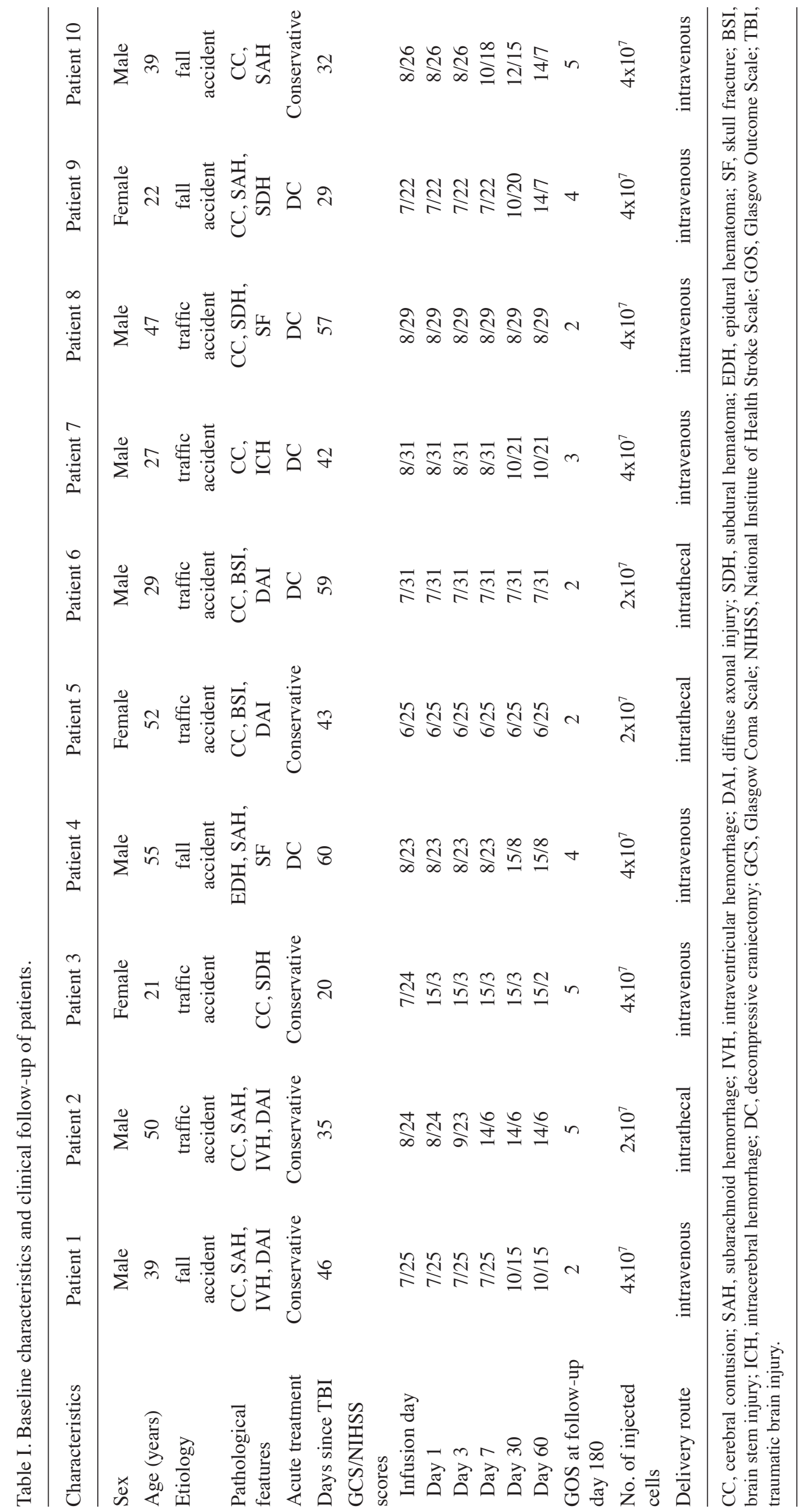


Table II. NGF and BDNF levels prior to and following transplantation.

\begin{tabular}{lccc}
\hline Factor & Baseline value & Day 3 post transplantation & Day 7 post transplantation \\
\hline Serum NGF $(\mathrm{pg} / \mathrm{ml})$ & $18.32 \pm 2.59$ & $21.46 \pm 3.18$ & $29.23 \pm 7.95^{\mathrm{b}}$ \\
Serum BDNF $(\mu \mathrm{g} / \mathrm{ml})$ & $26.16 \pm 8.28$ & $32.50 \pm 8.70^{\mathrm{a}}$ & $41.85 \pm 13.8^{\mathrm{b}}$ \\
\hline
\end{tabular}

Data are presented as the mean \pm standard deviation of all patients. ${ }^{\mathrm{P}}<0.05 \mathrm{vs}$. baseline value; ${ }^{\mathrm{b}} \mathrm{P}<0.01 \mathrm{vs}$. baseline value. NGF, nerve growth factor; BDNF, brain-derived neurotrophic factor.

Adverse events of the procedure. Serial clinical, laboratory and radiographic evaluations demonstrated no mortality or serious adverse events during the transplantation procedure or during the follow-up period (180 days). No significant hemodynamic or respiratory changes were immediately identified subsequent to NSC-like cell treatment. No new neurological deficits were detected in any patient after transplantation. Follow-up MRI evaluations did not demonstrate any new lesions or tumor development. In addition, no patients were newly diagnosed with arrhythmia or seizure during the follow-up period. Of the 10 patients, 1 patient presented a mild febrile reaction (temperature, $\leq 38.5^{\circ} \mathrm{C}$ ) a week after the NSC infusion. There was no evidence of septicemia in this patient; however, bacterial pneumonia was detected, and the patient was successfully treated with antibiotics. These results confirm the excellent tolerance to the procedure.

Neurological evaluation.Patients were followed up with standard clinical examination, as well as evaluation with NIHSS, GCS and GOS scoring. Table I shows a summary of all the values prior to and following transplantation of NSC-like cells. No signs of worsening in the neurological function were observed in any patient as a result of the introduction of NSC-like cells. In fact, during the follow-up period, 7 patients presented different degrees of improvement in neurological function, as compared with the values prior to transplantation. As shown in Table I, the NIHSS scores improved (range, -10 to -22 points) during follow-up in 7 patients, and the GCS scores also increased correspondingly (range, 2-8 points). A possible exception is patient 3, whose scores of GCS and NIHSS were evidently improved at 1 day post-infusion. However, these findings need to be interpreted with caution since no control group was used in this trial.

Serum levels of neurotrophic factors. Table II demonstrates the NGF and BDNF serum levels of patients measured at the beginning of the therapy, and at 3 and 7 days after the transplantation. The NGF levels detected at 3 or 7 days after transplantation were comparable between patients. Post-hoc comparisons between the beginning of therapy and at 7 days after transplantation revealed a significant increase $(\mathrm{P}<0.01)$ in the NGF levels. Compared with the pretransplantation values, the BDNF serum levels were also significantly increased at 3 and 7 days after cell transplantation $(\mathrm{P}<0.05$ and $\mathrm{P}<0.01$, respectively).

\section{Discussion}

The present phase I trial of intravenous or intrathecal administration of autologous MSC-derived NSC-like cells was designed to test the safety and feasibility of this potential treatment in patients with severe TBI. The results revealed that the procedure was tolerated quite well, and that there were no significant adverse events due to the presence of the NSC-like cells in the vessel or subarachnoid space. Furthermore, there was no evidence of tumor formation, venous thromboembolism, intracranial infection or systemic infection in any of the patients following autologous human NSC-like cells transplantation. Mild fever that was attributed to bacterial pneumonia was observed in 1 patient.

The neurological scores (NIHSS and GCS) of 7 patients improved at the end of the follow-up period. In patient 3, the scores of GCS and NIHSS improved distinctly at 1 day after NSC treatment, showing significant recovery of neurological function. Although this result is promising as it demonstrates rapid recovery of neurological function in 1 patient, it must be interpreted with caution since there was no control group in the present trial. A certain degree of clinical recovery occurred in the majority of patients who underwent post-autologous human NSC-like cell transplantation; however, it is emphasized that the possibility of spontaneous recovery, without any other treatment, cannot be excluded in these patients.

Previous studies have demonstrated that transplanted NSCs ameliorated the neurological deficits and promoted the restoration of neurological function in animal models of TBI (21-23). Several underlying mechanisms of action have been suggested to explain these functional benefits following stem cell infusion. For instance, it has been suggested that transplanted NSCs may result in repair and restoration of neuronal circuitry through immunomodulatory effects $(24,25)$, the production of neurotrophic factors (26), the release of specific neurotransmitters (27), and/or potential cell replacement (28). Following TBI, neurons and glial cells die as a result of a combination of necrosis and apoptosis. Evidence from animal models suggests that a reduction in apoptosis in the ischemic boundary area occurs following NSC therapy that is associated with improved neurological functional recovery (29). In addition, it is possible that transplantation of stem cells may amplify the endogenous regeneration and plasticity responses, such as angiogenesis, neurogenesis and synaptogenesis (30-33). Previous experimental studies have reported that the secretion and upregulation of certain trophins by NSCs, including NGF, BDNF, bFGF, glial cell-line-derived factor and vascular endothelial growth factor, all of which were associated with neural repair and axonal regeneration $(34,35)$. Consistent with these findings, in the present trial, higher NGF and BDNF levels were detected in the serum subsequent to autologous NSC-like cell transplantation, supporting the hypothesis of the secretory function of NSCs. 
Although the transplantation of NSCs in severe TBI patients appears to be safe and feasible, numerous questions remain unanswered, including the optimum timing of therapy, best route of delivery, dose of cells, and the underlying mechanisms of action. Ma et al (36) indicated that a significant decrease in the number of surviving NSCs in rats undergoing transplantation at an early stage after TBI may be associated with the early post-traumatic environment, such as inflammatory cascades, while the blood-brain barrier disruption may mediate cell death and negatively affect the survival and migration of grafted stem cells $(37,38)$. In the present study, subacute or chronic patients were selected, since these patients were more stable, and transplantation was performed after the acute inflammation had subsided. Further studies are required to investigate the ideal timing of transplantation for optimum recovery benefit. In addition, the main limitations of the current study include the relatively small number of NSC cases included and the lack of a blinded, control group. For this reason, the possibility of placebo effects or recovery as a result of the natural history of TBI cannot be excluded in this trial.

In conclusion, 10 severe TBI patients were successfully treated with intravenous or intrathecal injection of human NSC-like cells in the present study. The current results indicated that all patients tolerated the procedure without major complications, and that the transplantation of autologous MSC-derived NSC-like cells is feasible and appears to be safe for the treatment of non-acute severe TBI. Furthermore, higher serum levels of neurotrophic factors were detected following NSC transplantation, which is a possible mechanistic pathway underlying the improved functional recovery. Further randomized clinical trials are necessary to establish the efficacy and long-term safety of this procedure.

\section{Acknowledgements}

The present study was supported by the Science and Technology Bureau of Jingmen (grant no. 2012YD34).

\section{References}

1. Langlois JA and Sattin RW: Traumatic brain injury in the United States: Research and programs of the centers for disease control and prevention (CDC). J Head Trauma Rehabil 20: 187-188, 2005

2. Maas AI, Stocchetti N and Bullock R: Moderate and severe traumatic brain injury in adults. Lancet Neurol 7: 728-741, 2008.

3. Tagliaferri F, Compagnone C, Korsic M, Servadei F and Kraus J: A systematic review of brain injury epidemiology in Europe. Acta Neurochir (Wien) 148: 255-268, 2006

4. Langlois JA, Rutland-Brown W and Wald MM: The epidemiology and impact of traumatic brain injury: A brief overview. J Head Trauma Rehabil 21: 375-378, 2006.

5. Badri S, Chen J, Barber J, Temkin NR, Dikmen SS, Chesnut RM, Deem S, Yanez ND and Treggiari MM: Mortality and long-term functional outcome associated with intracranial pressure after traumatic brain injury. Intensive Care Med 38: 1800-1809, 2012.

6. Lindvall $\mathrm{O}$ and Kokaia Z: Stem cells for the treatment of neurological disorders. Nature 441: 1094-1096, 2006.

7. Wang E, Gao J, Yang Q, Parsley MO, Dunn TJ, Zhang L, DeWitt DS, Denner L, Prough DS and Wu P: Molecular mechanisms underlying effects of neural stem cells against traumatic axonal injury. J Neurotrauma 29: 295-312, 2012.

8. Yan ZJ, Zhang P, Hu YQ, Zhang HT, Hong SQ, Zhou HL, Zhang MY and Xu RX: Neural stem-like cells derived from human amnion tissue are effective in treating traumatic brain injury in rat. Neurochem Res 38: 1022-1033, 2013.
9. Anbari F, Khalili MA, Bahrami AR, Khoradmehr A, Sadeghian F, Fesahat $\mathrm{F}$ and Nabi A: Intravenous transplantation of bone marrow mesenchymal stem cells promotes neural regeneration after traumatic brain injury. Neural Regen Res 9: 919-923, 2014.

10. Guan J, Zhu Z, Zhao RC, Xiao Z, Wu C, Han Q, Chen L, Tong W, Zhang J, Han Q, et al: Transplantation of human mesenchymal stem cells loaded on collagen scaffolds for the treatment of traumatic brain injury in rats. Biomaterials 34: 5937-5946, 2013.

11. Liu Y, Yi XC, Guo G, Long QF, Wang XA, Zhong J, Liu WP, Fei Z, Wang DM and Liu J: Basic fibroblast growth factor increases the transplantation-mediated therapeutic effect of bone mesenchymal stem cells following traumatic brain injury. Mol Med Rep 9: 333-339, 2014.

12. Glass JD, Boulis NM, Johe K, Rutkove SB, Federici T, Polak M, Kelly $\mathrm{C}$ and Feldman EL: Lumbar intraspinal injection of neural stem cells in patients with amyotrophic lateral sclerosis: Results of a phase I trial in 12 patients. Stem Cells 30: 1144-1151, 2012

13. Karussis D, Karageorgiou C, Vaknin-Dembinsky A, Gowda Kurkalli B, Gomori JM, Kassis I, Bulte JW, Petrou P, Ben Hur T, Abramsky O and Slavin S: Safety and immunological effects of mesenchymal stem cell transplantation in patients with multiple sclerosis and amyotrophic lateral sclerosis. Arch Neurol 67: 1187-1194, 2010.

14. Chen G, Wang Y, Xu Z, Fang F, Xu R, Wang Y, Hu X, Fan L and Liu H: Neural stem cell-like cells derived from autologous bone mesenchymal stem cells for the treatment of patients with cerebral palsy. J Transl Med 11: 21, 2013.

15. Stabenfeldt SE, Irons HR and Laplaca MC: Stem cells and bioactive scaffolds as a treatment for traumatic brain injury. Curr Stem Cell Res Ther 6: 208-220, 2011.

16. Teasdale G and Jennett B: Assessment of coma and impaired consciousness. A practical scale. Lancet 2: 81-84, 1974.

17. Ma K, Fox L, Shi G, Shen J, Liu Q, Pappas JD, Cheng J and $\mathrm{Qu}$ T: Generation of neural stem cell-like cells from bone marrow-derived human mesenchymal stem cells. Neurol Res 33: 1083-1093, 2011.

18. Jennett B and Bond $\mathrm{M}$ : Assessment of outcome after severe brain damage. Lancet 1: 480-484, 1975.

19. Ver Hage: The NIH stroke scale: a window into neurological status. Nurse Com Nursing Spectrum (Greater Chicago) 24: 44-49, 2011.

20. Brain Trauma Foundation; American Association of Neurological Surgeons; Congress of Neurological Surgeons: Guidelines for the management of severe traumatic brain injury. J Neurotrauma 24 (Suppl 1): S1-106, 2007. Erratum in: J Neurotrauma 25: 276-278, 2008.

21. Riess P, Zhang C, Saatman KE, Laurer HL, Longhi LG, Raghupathi R, Lenzlinger PM, Lifshitz J, Boockvar J, Neugebauer E, et al: Transplanted neural stem cells survive, differentiate, and improve neurological motor function after experimental traumatic brain injury. Neurosurgery 51: 1043-1054, 2002

22. Shear DA, Tate MC, Archer DR, Hoffman SW, Hulce VD, Laplaca MC and Stein DG: Neural progenitor cell transplants promote long-term functional recovery after traumatic brain injury. Brain Res 1026: 11-22, 2004.

23. Skardelly M, Gaber K, Burdack S, Scheidt F, Hilbig H, Boltze J, Förschler A, Schwarz S, Schwarz J, Meixensberger J and Schuhmann MU: Long-term benefit of human fetal neuronal progenitor cell transplantation in a clinically adapted model after traumatic brain injury. J Neurotrauma 28: 401-414, 2011.

24. Fujiwara Y, Tanaka N, Ishida O, Fujimoto Y, Murakami T, Kajihara H, Yasunaga Y and Ochi M: Intravenously injected neural progenitor cells of transgenic rats can migrate to the injured spinal cord and differentiate into neurons, astrocytes and oligodendrocytes. Neurosci Lett 366: 287-291, 2004.

25. Pluchino S, Zanotti L, Rossi B, Brambilla E, Ottoboni L, Salani G, Martinello M, Cattalini A, Bergami A, Furlan R, et al: Neurosphere-derived multipotent precursors promote neuroprotection by an immunomodulatory mechanism. Nature 436: 266-271, 2005.

26. Harting MT, Sloan LE, Jimenez F, Baumgartner J and Cox CS Jr: Subacute neural stem cell therapy for traumatic brain injury. J Surg Res 153: 188-194, 2009.

27. Karimi-Abdolrezaee S, Eftekharpour E, Wang J, Morshead CM and Fehlings MG: Delayed transplantation of adult neural precursor cells promotes remyelination and functional neurological recovery after spinal cord injury. J Neurosci 26: 3377-3389, 2006. 
28. Chu K, Kim M, Park KI, Jeong SW, Park HK, Jung KH, Lee ST, Kang L, Lee K, Park DK, et al: Human neural stem cells improve sensorimotor deficits in the adult rat brain with experimental focal ischemia. Brain Res 1016: 145-153, 2004.

29. Lladó J, Haenggeli C, Maragakis NJ, Snyder EY and Rothstein JD: Neural stem cells protect against glutamate-induced excitotoxicity and promote survival of injured motor neurons through the secretion of neurotrophic factors. Mol Cell Neurosci 27: 322-331, 2004.

30. Caplan AI: Adult mesenchymal stem cells for tissue engineering versus regenerative medicine. J Cell Physiol 213: 341-347, 2007.

31. Harting MT, Baumgartner JE, Worth LL, Ewing-Cobbs L, Gee AP, Day MC and Cox CS Jr: Cell therapies for traumatic brain injury. Neurosurg Focus 24: E18, 2008.

32. Maegele M and Schaefer U: Stem cell-based cellular replacement strategies following traumatic brain injury (TBI). Minim Invasive Ther Allied Technol 17: 119-131, 2008.

33. Schouten JW, Fulp CT, Royo NC, Saatman KE, Watson DJ, Snyder EY, Trojanowski JQ, Prockop DJ, Maas AI and McIntosh TK: A review and rationale for the use of cellular transplantation as a therapeutic strategy for traumatic brain injury. J Neurotrauma 21: 1501-1538, 2004.
34. Gao J, Prough DS, McAdoo DJ, Grady JJ, Parsley MO, Ma L, Tarensenko YI and Wu P: Transplantation of primed human fetal neural stem cells improves cognitive function in rats after traumatic brain injury. Exp Neurol 201: 281-292, 2006.

35. Lu P, Jones LL, Snyder EY and Tuszynski MH: Neural stem cells constitutively secrete neurotrophic factors and promote extensive host axonal growth after spinal cord injury. Exp Neurol 181: 115-129, 2003.

36. Ma H, Yu B, Kong L, Zhang Y and Shi Y: Transplantation of neural stem cells enhances expression of synaptic protein and promotes functional recovery in a rat model of traumatic brain injury. Mol Med Rep 4: 849-856, 2011.

37. Lenzlinger PM, Morganti-Kossmann MC, Laurer HL and McIntosh TK: The duality of the inflammatory response to traumatic brain injury. Mol Neurobiol 24: 169-181, 2001.

38. Modo M, Stroemer RP, Tang E, Patel S and Hodges H: Effects of implantation site of stem cell grafts on behavioral recovery from stroke damage. Stroke 33: 2270-2278, 2002. 